Article

\title{
James Joyce and the Epiphanic Inscription: Towards an Art of Gesture as Rhythm
}

\author{
Alberto Tondello \\ Department of English, University College London, London WC1E 6BT, UK; alberto.tondello.17@ucl.ac.uk
}

Received: 7 September 2018; Accepted: 30 October 2018; Published: 3 November 2018

\begin{abstract}
In Agency and Embodiment, Carrie Noland describes gesture as "a type of inscription, a parsing of the body into signifying and operational units", considering it as a means to read and decode the human body. Through an analysis of James Joyce's collection of Epiphanies, my paper will examine how gesture, as a mode of expression of the body, can be transcribed on the written page. Written and collected to record a "spiritual manifestation" shining through "in the vulgarity of speech or gesture, or in a memorable phase of the mind itself", Joyce's Epiphanies can be considered as the first step in his sustained attempt to develop an art of gesture-as-rhythm. These short pieces appear as the site in which the author seeks, through the medium of writing, to negotiate and redefine the boundaries of the physical human body. Moving towards a mapping of body and mind through the concept of rhythm, and pointing to a collaboration and mutual influence between interiority and exteriority, the Epiphanies open up a space for the reformulation of the relationship between the human body and its environment. Unpacking the ideas that sit at the heart of the concept of epiphany, the paper will shed light on how this particular mode of writing produces a rhythmic art of gesture, fixing and simultaneously liberating human and nonhuman bodies on the written page.
\end{abstract}

Keywords: James Joyce; Epiphanies; gesture; inscription; rhythm; ellipses

\section{Epiphanic Inscriptions ${ }^{1}$}

The relationship between gesture and writing is not a straightforward one to define. While both are ways of communication, the transience and dynamism of gesture can easily be opposed to the permanence and stability of writing. In The Speech-Gesture Complex, Anthony Paraskeva stresses from the very early pages the difficulty of rendering gestures in written form, claiming that "the visuality that gesture requires can never be adequately or unequivocally represented in literature" (Paraskeva 2013, p. 3). According to Paraskeva, modernist writers were particularly aware that "language cannot represent the visual form of gesture, and gesture cannot use the categories of discursive language to signify and convey meaning" (Paraskeva 2013, p. 4). As he shows, however, this awareness did not discourage writers such as Kafka, Joyce, or Beckett from trying to transcribe bodily movements on the page. Conscious of the potential failure of this endeavour, these writers play with the limitations and possibilities of writing, generating styles which might accommodate new relations between words and gestures, between the seemingly fixed inscription of the written page and the fleeting movements of the body. The short fragments which James Joyce composed between

1 In the article, the term "inscription" will always be linked to the act of writing, therefore referring to the action of inscribing words on a page. Used in the context of Joyce's Epiphanies, the term is meant to stress the idea of permanence. As it will be further explained, by tracing signs upon a surface (in this case a blank page), Joyce aimed at recording and collecting specific moments of his life, fixing them on the written page. 
1900 and 1904 and called Epiphanies are an example of this attempt. ${ }^{2}$ These sketches, "hardly ever more than a dozen lines in length, but always very accurately observed and noted, the matter being so slight" (Joyce 2009, p. 134), appear as the textual rendition of the broader concept of epiphany, given by Stephen Daedalus in Stephen Hero. In the early version of A Portrait of the Artist as a Young Man, written between 1904 and 1906, the character defines an epiphany as

a sudden spiritual manifestation, whether in the vulgarity of speech and gesture or in a memorable phase of the mind itself. He believed that it was for the man of letters to record these epiphanies with extreme care, seeing that they themselves are the most delicate and evanescent of moments. (Joyce 1963, p. 211)

As it concerns "not just the experience but the written account of that experience" (Slote 2005), the term epiphany can easily generate confusion, but it can equally offer a fruitful opportunity to explore the link between lived experience and written record. ${ }^{3}$ While texts normally have the "propensity to reduce gestures to codified signs and the body to the status of a readable document" (Paraskeva 2013, p. 4), the Epiphanies seem to fight against this textual inclination, playing with the visual and discursive abilities of language in the attempt to maintain the kinaesthetic quality of gestures without fixing them into a standardised code. Thus, the Epiphanies composed by Joyce can be considered as a singular kind of written inscription, one that is able to reconcile the stable and durable marking normally associated with the act of inscribing on a page, with the transient nature of bodily gestures. A particular vision of language emerges from these short sketches, one in which body and language, physical and textual movements intermingle in the process of signification. ${ }^{4}$

\section{Gestures and Words, Seeking New Rhythms}

Throughout his writing career, James Joyce maintained a fascination for the communicative and expressive abilities of gestures, offering a first definition of the term as early as Stephen Hero. In the unpublished novel, Stephen tells his friend Cranly that "there should be an art of gesture [... ] of course I don't mean an art of gesture in the sense that the elocution professor understands the word. For him a gesture is an emphasis. I mean a rhythm". (Joyce 1963, p. 184) Shifting the focus from "emphasis" to "rhythm", Stephen sets himself against the elocution professor, but also against a concept of gesture which was widespread in the late 19th century. In her book devoted to gestures as stereotype and parody in the works of Joyce, Christy L. Burns traces the conception of gesture-as-emphasis back

2 Throughout the article I will capitalise the term Epiphany when referring to Joyce's sketches, in order to differentiate the textual composition from the more general concept and theory of epiphany as presented in Stephen Hero.

3 As Vicky Mahaffey points out, "the main difficulty presented by the Epiphanies lies in the broad application of the word itself, which Joyce used not only to designate the slivers of life that he punctiliously preserved in prose and dialogue from 1900 to 1903, but also as a metaphor, drawn from classical and Christian myth, for the revelation of the spiritual and the actual" (Attridge 2004, pp. 176-77). Critics have followed two main approaches in their analysis of the epiphany within Joyce's writing. Criticism on the theory as exposed by Stephen in Stephen Hero (Joyce 1963, pp. 211-13) has often considered the theory in its ties with ideas on beauty and aesthetics by Aristotle or Aquinas. Notable examples include Maurice Beebe "Joyce and Aquinas: The Theory of Aesthetic" Philological Quarterly (Beebe 1957); S.L. Goldberg The Classical Temper (Goldberg 1961); Morris Beja Epiphany in the Modern Novel (Morris 1971); William T. Noon Joyce and Aquinas (Noon 1957). The second common approach considers the theory of epiphany and Joyce's own fragments in relation to Joyce's subsequent texts. Irene Hendry (Hendry 1946) is amongst the first to consider the theory of epiphany in relation with other texts by Joyce, advancing the claim that "Joyce's work is a tissue of epiphanies" (Hendry 1946, p. 461). In her study "A Portrait of James Joyce's Epiphanies as a Source Text", Ilaria Natali examines the changes which several of the original fragments undergo when included in a broader narrative (Natali 2011). A similar enterprise, limited to only two epiphanies, had been undertaken by Robert Scholes in his essay "Joyce and the Epiphany: The Key to the Labyrinth?", The Sewanee Review, 72/1 (Scholes 1964, pp. 74-77). Overall, as Mahaffey claims, "criticism has tended to favour the concept of epiphany over the prose sketches that bear the same name" (Attridge 2004, p. 179). My article parts from these tendencies, focusing almost exclusively on Joyce's fragments.

4 This vision of language can easily be aligned with Merleau-Ponty's phenomenological approach to language, as developed in Signes (Merleau-Ponty 1960), and Phénoménologie de la Perception (Merleau-Ponty 1945). Conscious that a direct engagement with such theories goes beyond the limited span of this article, I chose to engage with Kristeva's essay "Gesture: Practice or Communication" to develop this line of thought. Kristeva's essay draws from the phenomenological tradition of Husserl and Merleau-Ponty, while focusing more specifically on gestures. 
to Bell's Standard Elocutionist, an influential manual published in 1878 which attempted to standardise the theoretical and practical principles for reading and recitation. As Burns notices, the book portrays "in a section on bodily gestures an art quite opposite that of Stephen's, rigidly codifying bodily poise, foot placement, and other forms of posture" (Burns 2000, p. 27). An art of gesture as envisioned by Bell and by Stephen's elocution professor focuses on gestures which are easily codifiable, as they are carefully performed to complement dramatic recitation. While the conception of gesture-as-emphasis considers bodily movements as subordinate to the communicative abilities of language, working as a support or embellishment of a meaning conveyed by words, gesture-as-rhythm seems to define the relationship between bodily movements and words in a radically different way. Gestures are not seen as an additional support to a meaning already defined by language, but actively help to constitute such meaning. The shift from emphasis to rhythm is synonymous with a passage from gesture as mechanical "accessory representation" to gesture as process. ${ }^{5}$ As Burns claims, "Joyce figures gesture as mime, dance, and eurhythmics, all processes that depend on the physical incorporation of a text into 'one own's self' [ ... ] gesture is therefore not some thing added onto a preestablished meaning, but a processual notion" (Burns 2000, pp. 22, 27). By insisting on the importance of rhythm over emphasis, Stephen stresses the processual nature of gesture, and paves the way for the possibility of rendering the visual and dynamic nature of gestures in his writing.

Rather than being exclusively related to the realm of sound, rhythm defines, for Joyce and for Stephen, a structural relation connecting different parts to a whole. While in the Paris Notebook Joyce sees rhythm as "the first or formal relation of part to part in any whole or of a whole to its part or parts, or of any part to the whole of which it is a part" (Joyce 2008, p. 103), in Stephen Hero Stephen defines rhythm as "the aesthetic result of the senses, values and relations of the words thus conditioned" (Joyce 1963, p. 25). According to Scarlett Baron, these definitions prove that Joyce contemplates the broader significance of the notion of rhythm, considering it as "a structural relation, a function of the relations of parts, or units, to the greater whole of which they are part" (Baron 2016, p. 26). For Joyce, the disposition of words and sentences is able to condition their value and determine not only patterns of sound and meter, but also patterns of signification. As the meaning of words is conditioned by the relations with other words, a certain fluidity is maintained within the fragment, a fluidity that in turns accommodates the movements of the body. In "Gesture: Practice or Communication", Julia Kristeva points out how gesture is "the elaboration of the message, the work which precedes the constitution of the sign (of the meaning) in communication" (Kristeva 1978, p. 267). Differentiating between "practice-productivity and communication-significance", Kristeva places gestures before the meaning conveyed by written and verbal communication, in a process of preparation in which gestures appear as not yet fully constituted signs, in a phase of potentiality anterior to any fixed meaning. In his sketches, Joyce manages to maintain a similar phase of potentiality and elaboration as a result of his extended notion of rhythm. Even as they are put down on paper, words continue to relate to each other, appearing as signs whose meaning is still in the process of formation. Laurent Milesi remarks that in the writing of Joyce "product (signification, oeuvre) [ ... ] has given way to production or process (significance, text or écriture) - including in the sense of the fascination of Joyce's "embodied" language for the materiality of bodily productions" (Milesi 2009, p. 9). As the Epiphanies show, if considered in relation to language, the idea of gesture-as-rhythm destabilises rigid codification, leaving a space for multiple signifying possibilities without cutting them off the moment words are inscribed on the page.

Unsurprisingly, the concept of epiphany itself has often been equated to the idea of gesture. According to Jackson L. Cope, "'Gesture' in the sense of a revealing rhythm [ ... ] seems to me that expressive cornerstone of what he meant by an epiphany" (Cope 1962, p. 73). In his article "Joycean Choreo-graphies", Laurent Milesi sees the epiphany as "a gesture recording kinetically—or

5 See Kristeva (1978, p. 266). 
precisely, as etymology tells us, e-motively (from e[x]-movere: to move out, set in motion, stir up) - the intrusion of the vivid external reality of lived experience into the realm of artistic expression, the successful embodiment of something real and objective into something linguistic and subjective" (Milesi 2010, p. 105). Similarly, Goldberg asserts that "an 'epiphany' is basically a 'gesture', an act of the total personality of the maker, which 'renders visible' what is there to be revealed in reality -an "entelechy" - by and in the medium of a constructed "structural rhythm"" (Goldberg 1961, p. 223). Focusing on small and subtle gestures, using bodily movements as the structural framework for the expression of thoughts and feelings, Joyce's Epiphanies can be considered as an early attempt to develop the notion of gesture-as-rhythm in written form, to put such an art of gesture into textual practice. Trying, through the rhythm of words and sentences, to mimic significant motions of the body, Joyce creates a particular correspondence between written words and the human body, exploring the ways in which both are able to communicate and relate to each other. Advancing the vision of gesture-as-rhythm, and of rhythm as relation of part to part, the Epiphanies recreate the "visuality which gesture requires" (Paraskeva 2013, p. 3) by associating bodily movements with textual gaps created by ellipses, or by building semantic and phonetic connections between words. If it is true that gestures are "the very stuff epiphanies are made of" (Bénéjam 1997), an analysis of some of Joyce's own Epiphanies will cast a light on the ways in which gestures can be transcribed, showing how language starts to be shaped and conditioned by gestures, rather than gestures by language.

Following Stephen's definition of epiphany in Stephen Hero, Robert Scholes and Richard M. Kain's separate Joyce's Epiphanies into "narrative", representing "a memorable phase of the mind", and "dramatic", focusing more on the "vulgarity and speech and gesture" (Joyce 1991, pp. 157-58). In spite of this clear demarcation which would confine gestures to the second category, I believe the two types of Epiphanies to be complementary for an exhaustive understanding of the ways in which Joyce inscribes gestures within the epiphanic fragments. While in the dramatic Epiphanies gestures are more easily identifiable, as they appear in the form of stage directions which are part of the dialogues recorded, the narrative Epiphanies are often structured around small gestures which, rendered through repetition of words and sentences, guide their movement and time of unfolding. In both cases, what emerges is a rendering of gestures corresponding to Stephen's definition of gesture-as-rhythm rather than emphasis, a conception which is able to reshape the relation between bodily movements and written words.

\section{Dramatic Epiphanies: Symptomatic Gestures and Ellipses}

The so-called dramatic Epiphanies record instances of what were almost certainly longer conversations. The particular composition of the fragments, presenting the interlocutors speaking as characters of a play and their gestures as stage directions, makes them appear as excerpts taken from longer theatrical scripts. Real people who were part of Joyce's early life are seen (or read) "titter[ing]", "walking noisily with thick boots", "smiling adroitly", "lean[ing] forward to speak seriously", "gripping [a] stick" and "moving [it] up and down", "crimson, trembling", "musing", "half kneeling, taking his hand" (Joyce 1991, pp. 161-98). From these examples, it is clear that the gestures accompanying the dialogues of the dramatic Epiphanies are never grandiose or out of the ordinary, but rather subtle and almost negligible. This common characteristic sits at the core of the concept of epiphany, as the moment preceding Stephen's definition of the term in Stephen Hero testifies. Hearing a "fragment of colloquy" similar to the ones recorded in the dramatic Epiphanies, Stephen "received an impression keen enough to afflict his sensitiveness very severely" (Joyce 1963, p. 211). Rather than something out of the ordinary, it is precisely the "triviality" of the conversation which "made him think of collecting such moments together in a book of epiphanies" (Joyce 1963, p. 211). Making Stephen's resolution concrete, Joyce observes the quotidian and apparently trivial exchanges of words and gestures and collects them in his own series of Epiphanies. While he clearly shapes his dramatic Epiphanies on the theatrical form of the play, he seems to take a definite distance from what Paraskeva defines as the "aggressive grand gestures of Irish heroic mythology" and the 
"heroic grand style of Irish Revivalism" (Paraskeva 2013, p. 54). Instead, his attention focuses on those small, everyday gestures which are not fully codified and are not meant to emphasise spoken words, bringing to mind what Sigmund Freud has defined as symptomatic actions. According to Freud, these actions "must not be striking, and their effects must be insignificant [ ... ] They give expression to something which the actor himself does not suspect in them, and which as a rule has no intention of imparting to others, but aims to keep to himself". (Freud 2003, p. 125) It is in similar terms that Stanislaus Joyce defines the Epiphanies, describing the collected moments as "slips, and little errors, and gestures-mere strains in the mind - by which people betrayed the very things they were most careful to conceal" (Joyce 2009, pp. 124-25). Employing a terminology reminiscent of Freud's, and underlying his brother's interest in "the revelation and importance of the subconscious" (Joyce 2009, p. 125), Stanislaus Joyce seems to confirm the similarities between Freud's symptomatic gestures, and the gestures which caught Joyce's attention and led him to the decision to collect them. In Epiphany 4, for instance, Aunt Lillie's tittering has the double effect of fragmenting the exposition of her youthful intention, and of betraying a nervous amusement behind her personal confession: "Aunt Lillie — (titters) - O laus! ... .I was like that too ........ When I was a girl I was sure I'd marry a lord ... or something ..." (Joyce 1991, p. 164). ${ }^{6}$ A similar effect is produced by the gestures of the Lame Beggar in Epiphany 15

The Lame Beggar — (gripping his stick) ... . It was you who called after me yesterday.

The Two Children — (gazing at him) ... No, sir.

The Lame Beggar - O, yes it was, though ... (moving his stick up and down) ... .But mind what I'm telling you .... D'ye see that stick?

The Two Children - Yes, sir.

The Lame Beggar — Well, if ye call out after me any more I'll cut ye open with that stick.

$$
\text { (Joyce 1991, p. 175) }
$$

The small gesture of gripping the stick reveals the beggar's nervousness, while the moving of the stick up and down invests a potentially neutral statement with a menacing tone. The beggar's bodily movement precedes his verbal threat, which appears as a semantic follow-up to the movement of the stick. ${ }^{7}$ If theatrical gestures placed themselves in a well-defined circuit of meaning and signification and were used to outwardly emphasise the words spoken by actors, the small and elusive gestures recorded by Joyce are able to reveal the hidden motives of the speaker, moving from a studied consolidation of meaning to a subconscious dissemination of information.

While some gestures offer themselves to easy interpretation, it is overall extremely difficult to recognise what exactly is being betrayed by the gestures, words, or thoughts recorded in the Epiphanies. If these moments produced on Joyce "an impression keen enough to afflict his sensitiveness very severely", it is almost impossible to retrace the reasons behind his decision to record them. As Nichols claims, "the modern epiphany emphasises the perception of significance rather than the interpreted meaning of the significant moment" (Nichols 1978, p. 3). We can argue that these moments and conversations are somehow important as they have been recorded, but it is almost impossible to assert why or how exactly they were meaningful to Joyce. In a similar way, due to the highly personal nature of this process, and the absence of any standardised code which could invest each gesture with a particular meaning, the information the gestures reveal is rarely brought to the fore. Rather than using

6 In this article, I will follow the numbering adopted by O.A. Silverman (Joyce 1956), and later on by Richard Ellmann, A. Walton Litz, and John Whittier-Ferguson (Joyce 1991).

7 Sticks, and the gestures related to them, seem to have particular relevance in the works of Joyce. In Ulysses, Stephen is almost inseparable from his ashplant, while Bloom uses his Freeman to create a baton. The blind piano tuner similarly wanders around the streets of Dublin tapping with his cane. Helen $R$. Whaley examines the importance of these sticks in the novel, pointing out how they all seem "filled with creative power of one sort or another" (Whaley, p. 535). 
written language to standardise and disclose the meaning of these small gestures, Joyce's epiphanic inscriptions seem to mimic in their composition the veiled revelation triggered by them. If it is true that similar gestures constitute the stage directions of Joyce's play Exiles, and are not far removed from an Ibsenite tradition; there is an important visual difference between them and the gestures of the dramatic Epiphanies. In Joyce's fragments, most of the stage directions presenting a gesture are followed or surrounded by ellipses. While similar dots of suspension are not absent from the narrative Epiphanies, they appear much more frequently in the dramatic ones, in a proliferation that seems to play a fundamental role in the process of inscribing gestures in the written page. If gesture-as-emphasis was unequivocally related to certain words spoken by actors, the gestures collected in the Epiphanies are linked to an absence of words. By cutting the central lines of the conversations which are recorded, those words which the grand theatrical gestures were meant to emphasise, Joyce makes it impossible to clearly relate gestures with corresponding spoken utterances. In so doing, he creates a new rhythm, a new relation between words and bodily movements based on evocation rather than on codified meaning. Take, for instance, Tobin's disquisition on marriage in Epiphany 9:

Tobin - (walking noisily with thick boots and tapping the road with his stick) ... .O there's nothing like marriage for making a fellow steady. Before I came here to the Examiner I used to knock about with fellows and boose .... . Now I've a good house and ... ... go home in the evening and if I want a drink ... . .. well, I can have it ... . My advice to every young fellow that can afford it is: marry young. (Joyce 1991, p. 169)

While Tobin's speech could unravel smoothly if the suspension dots were cut, the presence of ellipses complicates its reception, making it impossible to tell whether the pauses are due to an indecision from the part of the speaker, or an omission of information from the part of the writer. Thus, the ellipses create an open space of potential interpretation, while pointing to the inability of language to faithfully and unequivocally record lived moments. According to Michael Naas, ellipses offer "the impression of entering into the very intimacy that the narrator or author share with their work" (Naas 1996, p. 93). By disseminating ellipses in most of the dramatic Epiphanies, Joyce underlines their personal dimension, as the gaps work as a constant reminder that the subjective impressions which caught the author's attention won't be recovered by written words. The additional information which these gestures provided is now buried in the space of a few dots; a space, however, which is ultimately not a negation but an opening to new possibilities and relations, and becomes in itself a meaningful "linguistic" gesture. In her article on gestures, Kristeva introduces "the concept of interval: an emptiness, a jump, which does not oppose 'matter' (that is, acoustic or visual representation) but is identical to it" (Kristeva 1978, p. 272). Similarly, the void created by the ellipses is far from a meaningless pause, but seems to add a visual element that contributes at the level of signification. The most indicative example is probably given by Epiphany 19, one of the most touching Epiphanies concerning Joyce's brother George.

Mrs. Joyce - (crimson, trembling, appears at the parlour door) ... Jim!

Joyce - (at the piano) ... Yes

Mrs. Joyce - Do you know anything about the body? ... What ought I do? ... There's some matter coming away from the hole in George's stomach .... .

Joyce - (surprised) ... I don't know .... .

Mrs. Joyce - Ought I send for the doctor, do you think?

Joyce - I don't know ... what hole?

Mrs. Joyce - (impatient) ... The hole we all have ... here (points)

Joyce - (stands up). 
At first, there seems to be a contrast between the sense of urgency which emerges from the dialogue, and the slow movement of suspension created by the pauses, as the ellipses following the stage directions seem to be inconsistent with both Joyce's surprise and Mrs. Joyce's impatience. This discrepancy would be unexplainable if the ellipses were simply meant to provide a pause in the talking of the actors, a way to counterbalance noise and silence. However, this does not seem to be the function of suspension dots in this particular context. Rather than creating pauses of indecision, the ellipses produce an empty space which complements the full space of the written words, bringing the explicitly said and the unsaid onto the same level. Throughout the Epiphany, words are placed side by side the rhythmic movement of emotions, until they are replaced altogether by the gestures which conclude the dialogue. While the actual word which would describe the "hole we all have" is replaced by Mrs. Joyce's finger pointing to that particular part of the body, Joyce's movement of standing up is offered as a closing reaction, a voiceless remark. As Jesse Schotter notices, "a language of gestures would be purely embodied, with no gap between writing and human movement, but if Joyce cannot reach a purely gestural language when using the medium of writing, as Stephen Daedalus desires, then he must strive for a visual one" (Schotter 2010). The ellipses of the dramatic Epiphany seem to move precisely in that direction, rendering visible on the page the necessary gap between writing and human movement, while producing a visual rhythm which, as a "pulsating movement of 'concealment and revelation'" (Milesi 2010), makes this gap participate in the overall signification of the fragment.

The ellipses of the dramatic Epiphanies are the first example of Joyce's ability to use textual devices to highlight the limitations of written texts while simultaneously overcoming them. In "The Poetics of the Unsaid", Annalisa Volpone states that "Joyce's poetics of the unsaid represents the only possible way to transfer the totality of human experience into the written page, whereby incompleteness and displacement work as a strategy for overcoming the limits of language" (Volpone 2014, p. 90). Through the use of ellipses and gaps, Joyce points to the impossibility of rendering bodily movements through individual words, while at the same time going beyond it by inscribing gestures without fixing them to a particular word or meaning. While stage directions are normally meant to render visible on the page the actions that will be reproduced on stage, Joyce counterbalances this promise of appearance by creating typographical spaces of silence and invisibility. These spaces, however, offer the reader the possibility to mentally picture the gestures and guess their revelatory meanings, creating a rhythm between bodily gestures and words which goes beyond the written fragment. Through this new rhythm, rather than through emphasis, the symptomatic gestures recorded by Joyce might successfully be inscribed on the written page. As they do not reveal anything through standardisation and codification, the gestures of the dramatic Epiphanies are not described through words, or associated with specific sentences, but remain stuck in a stage of incompletion where words and gestures are inscribed on the page while they remain to a certain extent invisible and not fully restricted to the written fragment. Interestingly, the ellipses are removed altogether when the dramatic fragments are incorporated in a longer narrative. When the gestures leave the dramatic fragments, their movement and significance change. At this point, their original rhythm, the rhythm rendering these small gestures on the written page, loses most of its significance, as the focus shifts from the movement of the fragment to the development and unfolding of the longer narrative.

\section{Narrative Epiphanies: Gestures Guiding Narration}

A slightly different relation between gestures and words is created in the narrative Epiphanies. In the attempt to record dreams or "phases of the mind", the narrative Epiphanies appear as short prose poems, rather than as theatrical scripts. While gestures are not explicitly identified as in the dramatic Epiphanies, bodily movements appear at the core of these fragments, structuring them and guiding their movement and time of unfolding. In this type of Epiphanies, communication often happens through movements of the body, rendered and mimicked by repetition of words and sentences, or by 
the employment of what could be considered as an early version of portmanteau words. ${ }^{8}$ In Agency and Embodiment, Carrie Noland describes gesture itself as "a type of inscription, a parsing of the body into signifying or operational units" (Nolan 2009, p. 2), considering it as a way to read and decode the human body. By employing the verb "parse", normally used to describe the syntactic components of a sentence, Noland treats the body as a text which can be syntactically made sense of, dissected in its different units thanks to the gestures it performs. In the narrative Epiphanies, the operational units in which the body is inscribed become the syntactic units of the sentence, in a process that creates a secondary inscription which reproduces the rhythm of the body in the rhythmic composition of the page. In Epiphany 3, this process becomes particularly clear.

The children who have stayed latest are getting on their things to go home for the party is over. This is the last tram. The lank brown horses know it and shake their bell to the clear night in admonition. The conductor talks with the driver; both nod often in the free light of the lamp. There is nobody near. We seem to listen, I on the upper step and she on the lower. She comes up to my step many times and goes down again, between our phrases, and once or twice remains beside me, forgetting to go down, and then goes down ... Let be; let be .... And now she does not urge her vanities - her fine dress and sash and long black stockings - for now (wisdom of children) we seem to know that this end will please us better than any end we have laboured for. (Joyce 1991, p. 163)

In this fragment, communication happens mainly through movements and gestures. The children are warned that they are getting the last tram by the horses which "know it and shake their bell to the clear night in admonition". Two conversations take place, and both of them are defined not by the words exchanged, but by the movements of the speakers: the conductor and the driver "nod[ding] often in the free light of the lamp", while the girl, in the gesture which more than any other defines the rhythm of the Epiphany, moves up and down the step of the tram. While the conversation which accompanies the movement of the girl is not revealed, her gesture is not simply described but seems to be reproduced through pauses and repetitions. The rhythm is articulated by the words "go down", repeated three times and always followed by a pause mimicking the motion happening "between our phrases". Arresting the movement is another rhythmical reiteration separating the motion of the girl and the final sentence of the Epiphany: "... Let be; let be ... ". Divided by a semicolon and enclosed within ellipses, the invitation is expressed but not explained, acquiring importance not in virtue of its meaning, but because of its repetition and position. In a similar way, the motion of the girl is reproduced in its rhythm, but its significance is never spelled out. If a potential significance is precisely what distinguishes a gesture from a movement, the specific meaning of the girl's motion can only be guessed, in the same way as the overall meaning of the Epiphany is never specified and becomes a matter of conjecture. While the motion of the girl does not appear as a neutral displacement of her body, as it discloses a certain tension or awkwardness between the boy and the girl, it is hard to identify its actual significance with certainty. If in the dramatic Epiphanies the revelatory significance of the gestures remains unexpressed or is expressed simply by gaps in the text, the meaning of the gestures in the Epiphany above is not revealed, but simply rendered through the movement of the sentences and the repetition of key words. Thus, the transcription of gesture becomes a practice "of an indicative but not signifying type" (Kristeva 1978, p. 269), emerging before any potential meaning is cast on the written words. According to Kristeva, the basic function of gesture is anaphoric, as gesture "indicates, establishes relations" (Kristeva 1978, p. 270). Thought as rhythm, the gestures of the Epiphanies start to create a relation between words even as their signifying meaning remains unclear.

In his study, Paraskeva rightly points out that gestures "cannot use the categories of discursive language to signify and convey meaning" (Paraskeva 2013, p. 4). Joyce's Epiphanies seem to confirm

8 In James Joyce and the Difference of Languages, Milesi states that "One may even still register something of the former epiphany in the multi-layered portmanteau word or syntactico-rhythmic modulations of the Wake's nonce-idiom" (Milesi 2009, p. 2). 
this idea, as gestures are not described to signify or convey a particular meaning, but are able to rearrange words so that the rhythm of physical motions might be reproduced on the page. Not through meaning, but through connections between words, can writing attempt to inscribe the visual forms of gestures. In so doing, a gesture is not reduced to a sign but maintains its bodily and kinaesthetic qualities. This is apparent in Epiphany 23, describing the dancing of a boy.

[ ... ] He begins to dance far below in the amphitheatre with a slow and supple movement of the limbs, passing from movement to movement, in all the grace of youth and distance, until he seems to be a whirling body, a spider wheeling amid space, a star [ . . ] (Joyce 1991, p. 183)

The almost circular dancing of the boy is reproduced by the word "movement" itself, repeated three times in short sequence, and by the consonance of the words "whirling" and "wheeling" in subsequent sentences, words not only expressing analogous ideas but also reproducing similar sounds. As the boy's body moves round and round upon itself, the reader goes back to the same words and sounds, expressive of a gesture once more rhythmically conveyed through the disposition of words. A similar motion of circular dancing is portrayed in Epiphany 26, where the features of a dancing girl appear at the beginning and end of the Epiphany, in a circularity that is able to convey the effects of her dancing body.

She dances with them on the round - a white dress lightly lifted as she dances, a white spray in her hair; eyes a little averted, a faint glow on her cheek [ ... ] She dances with them on the round, evenly, discreetly, giving herself to no one. The white spray is ruffled as she dances, and when she is in shadow the glow is deeper on her cheek. (Joyce 1991, p. 186)

The repetition of the sentence "she dances with them on the round" highlights the continuous movement of the girl, while the reprise of the white spray in disarray and the intense tone of the glowing cheek suggest the effects produced by her prolonged dancing. Epiphany 24 evokes a subtler gesture, as the opening motion of an arm touching the knee of the narrator for an instant to then retract seems to work as a preamble for the development of the entire fragment. It is this simple gesture that triggers the intertextual echoes which appear in the Epiphany.

Her arm is laid for a moment on my knee and then withdrawn, and her eyes have revealed her - secret, vigilant, an enclosed garden - in a moment. I remember a harmony of red and white that was made for one like her, telling her names and glories, bidding her arise as for espousal, and come away, bidding her look forth, a spouse, from Amana and from the mountain of the leopards. And I remember that response whereunto the perfect tenderness of the body and the soul with all its mystery have gone: Inter ubera mea commorabitur. (Joyce 1991, p. 184)

Filled with intertextual references from the Song of Solomon, the entire fragment progresses in a constant movement of disclosure and concealment mimicking the first sudden gesture of the arm, extended and then withdrawn, as well as the eyes which reveal the girl's secrecy. All the references to the Song of Solomon - the enclosed garden, the red and white colours, Amana and the mountain of leopards, the image of the spouse - are disseminated in the Epiphany without being explained in any way, thus rendering through a veiled intertextual movement the soft touch which introduces the Epiphany. The closing sentence transcribes the retraction of the arm in written form. As the arm is laid and then withdrawn, the verse from the Vulgate Song of Solomon, left in Latin and not explained, creates a final, wider gap between the words of the Epiphany and their potential intelligibility.

As the decoding of the body in gestures is for Noland syntactical, established by the arrangement of "compositional units" rather than by the revelation of their potential meaning, the epiphanic inscriptions should be analysed in their structural rhythm, rather than for the potential significance of the images and moments which are recorded. According to David Hayman, "the structural rhythm is significant quite apart from the 'sense' the event may have" (Hayman 1993, p. 39). What "shines forth" 
in the epiphanic fragments is not any particular meaning nested within the shards of words that constitute them, but the relationships that can be established between words, sentences, and other texts, a rhythm which is shaped by and on the movement of bodies. When Stephen suggests that "there should be an art of rhythm" (Joyce 1963, p. 184) in Stephen Hero, he uses Ariel's song from The Tempest to explain what he means. Rather than explaining the meaning or significance of the poem, he reads Ariel's song with his own body, rendering its metrical form with the movements of his arms, "making a graceful anapaestic gesture with each arm" (Joyce 1963, p. 184). ${ }^{9}$ Joyce's Epiphanies are similarly built on a correspondence between gestures and words, between syntactical and bodily units. As both Stephen and Joyce seem to share the idea that "language needs to be wedded to the body to communicate more forcefully" (Burns 2000, p. 22), the Epiphanies appear as textual fragments inscribed with and through the body. Gestures do not emphasise written words or sentences, but produce the rhythm of the sketches themselves. This is made possible not only through the choice of words and their repetitions, as in the examples above, but also through a fluidity of signification maintained by certain words within the fragments.

\section{The Gestural Quality of Words}

In the Epiphanies, words acquire what I will define as a "gestural quality" determined by their ability to produce multiple connections between other words and ideas. While the dramatic Epiphanies trigger this process thanks to the rhythm created by ellipses, the narrative Epiphanies present sentences and words which motion towards an array of potential meanings without ever fixing on a single one. Employing linguistic signs which maintain a polysemic character even as they are written down in specific sentences, the epiphanic fragments inscribe on the page the gestural pre-constitution of signs, keeping intact the potentiality which characterises gestures. Epiphany 8 exemplifies this process:

Dull clouds have covered the sky. Where three roads meet and before a swampy beach a big dog is recumbent. From time to time he lifts his muzzle in the air and utters a prolonged sorrowful howl. People stop to look at him and pass on; some remain, arrested, it may be, by that lamentation in which they seem to hear the utterance of their own sorrow that had once its voice but is now voiceless, a servant of laborious days. Rain begins to fall. (Joyce 1991, p. 168)

The fragment is scanned by the movement and noises of a dog, which produces both the rhythm and the atmosphere of the scene as "from time to time he lifts his muzzle in the air and utters a prolonged sorrowful howl". Considered by William Martin as "a rhythmic gesture" (Martin 2012, p. 21), the dog's periodic lamentation defines the movement of the people around it, causing them to "stop to look at him and pass on" while "some remain, arrested". The "prolonged sorrowful howl" seems to confirm the idea that "affective and emotional states are not simply qualities of subjective experience, rather [... ] they are expressed in bodily gestures and actions, and they thereby become visible to others" (Zahavi 2007, p. 30). The cry of the dog, expressing the "voiceless" lamentation of the people, undefinable by words but rendered visible through one single repeated gesture, rings in tune with the general atmosphere of the Epiphany, created by the recurrence of words such as "sorrowful", "lamentation" and "sorrow", and the "dull clouds" which, menacing at the beginning of the Epiphany, release rain at the end of it. The choice to describe the clouds as "dull" is particularly interesting, as the adjective presents a multiplicity of meanings which can be related to the scene. If limited to the description of the clouds, the word most likely defines something "not clear or bright; cheerless, gloomy, overcast" (OED 2018). Several different layers can be added to this first designation, connecting the clouds to other elements in the Epiphany. Defining "a state approaching gloom, melancholy, or sadness"

9 In her analysis of the passage, Burns states that Stephen barely alludes to the song, taking only its elemental rhythm and running it through his own medium, the body, without explanation or verbal thematics. He mimes the sensual aspects of the song rather than its theme, perhaps conveying a mood, but without sounds or words (Burns 2000, p. 25). 
(OED 2018), the word allows the clouds to be related to the sorrowful howl of the dog and the mood of the people. Finally, the word can be synonymous with something "sluggish", linking the atmospheric condition of the sky with the "swampy beach" where the scene takes place. The different connotations of the words, and the significance they all have in relation to the epiphanic scene, exemplify its gestural quality, its openness to an array of potential significations. "Dull" manages to create a relation of part to part, what Joyce would define as a rhythm, played this time on the semantic level, linking the sensations of the dog and the people with the elements of the depicted scene's surrounding. Words like "dull" approximate the work of "elaboration of the message" done by gestures, indicating without fixing, creating connections between different elements, and laying bare the expressive potential of language. Rather than imposing a predetermined and fixed structure to fluid movements, Joyce's Epiphanies maintain their fluency intact through a constant play of different significations and meanings conveyed by individual words. The fluidity of this gestural language is one of the elements which is able to create a stronger link between the sensations and movements of subjects, and the scene's surroundings, gathering under the rhythm of the page these different elements, creating a collaboration and mutual influence between interiority and exteriority. In James Joyce and the Art of Mediation, David Weir points out how the concept of epiphany has often been considered a "mediating link between subject and object" (Weir 1996, p. 40). In his book, Weir recognises that "epiphany involves some correspondence, or mediation, between the world without and the world within" (Weir 1996, p. 40). The gestural quality of certain words creates a particular sound and rhythm which generates this kind of correspondence, as can be seen in Epiphany 25.

The quick light shower is over but tarries, a cluster of diamonds, among the shrubs of the quadrangle where an exhalation arises from the black earth. In the colonnade are the girls, an April company. They are leaving shelter, with many a doubting glance, with the prattle of trim boots and the pretty rescue of petticoats, under umbrellas, a light armoury, upheld at cunning angles. They are returning to the convent - demure corridors and simple dormitories, a white rosary of hours - having heard the fair promises of Spring, that well-graced ambassador. (Joyce 1991, p. 185)

In the short description of the girls leaving shelter, words are linked by more than a simple alliteration on the letters " $\mathrm{p}$ " and " $\mathrm{r}$ ". The particular choice of adjectives offers an illustration which is only apparently confined to their exterior looks and attire. "Prattle" mediates between boots and girls, connecting the sound of the moving boots on the wet ground with the chatter of the group of girls. In a similar way, the adjectives "pretty" to define the action of the petticoat, and "cunning" to describe the angles of the umbrella, communicate something about the girls as much as they do about their garments. An analogous effect is produced through the description of the convent as "demure corridors and simple dormitories, a white rosary of hours". This time, the attention is caught by the word "rosary", potentially referring to the botanical display of roses, echoing the "shrub" where raindrops hang like "a cluster of diamonds", and to the religious prayer to the Virgin Mary. This second denotation could clarify the expression "rosary of hours", linking the monotonous passing of time with the litany of repeated Hail Mary. The several connotations of different words manage to create a description encompassing various dimensions without ever fixing on a specific one, and are able to link the attitudes and bodies of the girls with their clothes.

A similar link, this time between a ferocious animal, its movements and the surround area, is created in Epiphany 28.

A moonless night under which the waves gleam feebly [... ] the sea is uneasy, charged with dull anger like the eyes of an animal which is about to spring, the prey of its own pitiless hunger. The land is flat and thinly wooded [ ... ] (Joyce 1991, p. 188)

A constant play of light and shadow, strength and weakness animates a sea acting like an animal. In the darkness of a moonless night, the glimmer of the waves is faintly visible, like the eye of a predator 
hiding in darkness, ready to ambush its prey. The central simile makes this comparison apparent, linking the unrest of the sea with the moment of tension preceding the animal's attack. The feeble gleam is thus opposed to the vigour of a sea "charged with dull anger". A similar contrast is kept in the following sentence, which is also able to keep the connection made by the central simile through the word "wooded". Etymologically, "wood" evokes the idea of going mad, of raging and become furious. While describing the calmness of the flat land surrounded by light trees, the word brings back the idea of the ferocious animal "about to spring", and links the apparently serene land with the charged sea. Creating a different connection, Epiphany 37 describes the sea as "mov[ing] with the sound of many scales". The word "scales" links the movement of the sea with the "bright, even voices of boys singing before the altar" appearing at the end of the fragment, bringing together in one word the scales of fish and musical scales, as Scarlett Baron has noted. ${ }^{10}$

"Before the sign" claims Kristeva "and before any problematics of significance (and so signifying structure), it has been possible to think of a practice of designation, a gesture which shows not to signify, but to englobe in one and the same space (without the dichotomies of idea-word, signified-signifier), let us say in one and the same semiotic text, 'subject' and 'object' and practice" (Kristeva 1978, p. 269). Some of the words animating the Epiphanies create such a space, shared by subject and object alike, characteristic of a practice which does not expire the possibilities of words as they are placed in a signifying structure, but keeps them alive and generates an inscription which maintains the vitality of a body. The epiphanic fragment attempts to reproduce this vitality and motion, showing in the written page the relations that can be established between physicality, words, and exterior environment; different parts of a whole brought together in what can truly start to be considered as an art of gesture-as-rhythm.

\section{Conclusions}

The interest in gestures which Joyce shows as early as Stephen Hero and the Epiphanies continues throughout his writing career. As Cope remarks, "rhythmic gesture reappears [in Ulysses], now defined both abstractly and in act" (Cope 1962, p. 74). In Joyce's novel, gestures continue to be associated with the idea of rhythm, and with a mutual collaboration between language and body. In her analysis of gestures in Ulysses, Guillemette Bolens refers to the mode and style of the novel as "corporeal" and "kinesic", "elaborated throughout the text through lexical and narrational moments of contact and disconnection, crossings and disappearances, allowing for the distant resonance of words by reverberation and vibration" (Bolens 2012, p. 50). In a description reminiscent of the resonances at play in the narrative Epiphanies, Bolens stresses the ability of words to create an overall structural rhythm. Confirming this connection is Stephen's definition of gesture as "a universal language, the gift of tongues rendering visible not the lay sense but the first entelechy, the structural rhythm" (Joyce 1963, $U$ 15.105-7) at the beginning of the "Circe" episode. Once again, gesture is seen as the means to generate a rhythm which is a connection of part to part, going beyond the signifying function of the linguistic sign in the direction of a universal understanding. A similar fascination for the relationship between language and gesture continues during the time of composition of Finnegans Wake, as Joyce attends at least one lecture by French anthropology Marcel Jousse, who considered gesture to be at the origin of language. Mary Colum remembers a lecture she attended with Joyce in 1929, recalling that "what was shown was that the word was shaped by gesture. Joyce was full of the subject and talked to me about the lecture as we went along to the café where my husband was waiting for us, but I can't remember what he said" (Colum and Patrick 1959, pp. 130, 131). While it would have been helpful if Colum could have remembered what Joyce actually said about the lecture, it is not at all surprising that the writer was "full of the subject". According to Jed Rasula, Joyce must have been particularly impressed “by Jousse's concept of words emanating from physical action" (Rasula 1997, p. 519). The idea that

10 See Baron (2012). 
gestures might generate words, or at least influence them, can be traced to Joyce's early writings. As the Epiphanies have shown, more than 20 years before his encounter with Jousse's theories, Joyce gives the first signs of the importance that the motions of the human body might have in relation to language. Lorraine Weir maintains that "what Joyce found in Jousse's work was not the concept of gesture itself, but a structure, a choreography, and a handful of elaborations which reaffirmed what he already knew" (Weir 1977, p. 322). Decades before encountering the work and theories of Marcel Jousse, Joyce was already working on the elaboration of what Laurent Milesi defined as "choreo-graphies", a rhythmically written dance where "components like 'emotion', 'rhythm', 'gesture' [ ... ] and finally 'epiphany', are made to interact" (Milesi 2010, p. 105). Working with the kinaesthetic and rhythmic potentials of language, Joyce's Epiphanies appear as a particular kind of inscription which exemplifies the practice of designation accomplished by gestures, rendering visible on the written page the possible traits of an art of gesture-as-rhythm. Shaped by gestures, presenting words which elaborate a message without ever establishing unequivocal signification, the Epiphanies offer a writing which expresses itself through the rhythms of pauses, letters, words, and sentences, extending to the written page the characteristics of a communication normally associated to the physical human body. This rhythm, as structural relation of part to part, manages, in turn, to lay bare the strong connections which can be established not only between the physical human body and the written text, but also between the sensations of the subject and the inanimate elements constituting the environment where the action takes place.

The fragment appears as a particularly apt type of text for the transcription of gestures, due to the fluidity which normally characterises it. Never published on their own, Joyce's Epiphanies can be considered as a hybrid between notes to be used for subsequent longer narratives, and polished, finished texts to be considered on their own. While the actual content of the Epiphanies is never heavily modified, there are some important syntactical changes taking place in the passage from fragment to broader narrative, something that happens to 23 of the 40 existing Epiphanies. Not only are the ellipses removed, but the main verbal tenses guiding the narration change, moving from the actuality of the present simple and the openness of gerunds, to the fixity of the past tense which characterises the longer narratives. While they record important moments, fixing them on the written page, the Epiphanies remain open to some degree of gestation. Developing from bodily movements and open for future development, this particular form of writing seems to develop from the Latin root "gerere", common to the words "gesture" and "gestation". After all, the supreme artist, Stephen tells us, is the person who can "disentangle the subtle soul of the image from its mesh of defining circumstances most exactly and 're-embody' it in artistic circumstances chosen as the most exact for it in its new office" (Joyce 1963, p. 78). From the very beginning of his writing career, Joyce seems to be doing exactly that. Deciding to collect trivial moments "together in a book of epiphanies" (Joyce 1963, p. 211), Joyce disentangles these lived instances from their original contexts to use them as material for the purpose of artistic creation. Starting to put into textual practice an art of gesture-as-rhythm through which letters, words, and blank spaces are artfully arranged; these moments are fixed on the page as they keep moving, following the rhythm of a gesture.

Funding: This research received no external funding.

Conflicts of Interest: The author declares no conflict of interest.

\section{References}

Attridge, Derek. 2004. The Cambridge Companion to James Joyce. Cambridge: Cambridge University Press. Baron, Scarlett. 2012. "Strandentwining Cable": Joyce, Flaubert, and Intertextuality. Oxford: Oxford University Press. Baron, Scarlett. 2016. Joyce and the Rhythms of the Alphabet. In New Quotatoes: Joycean Exogenesis in the Digital Age. Edited by Ronan Crowley and Van Hulle. Leiden: Brill, pp. 18-44.

Beebe, Maurice. 1957. Joyce and Aquinas: The Theory of Aesthetic. Philological Quarterly 36: 20-35.

Morris, Beja. 1971. Epiphany in the Modern Novel. Washington: University of Washington Press. 
Bénéjam, Valérie. 1997. The Beau Geste: Molly's Generous White Arm. Paper presented at XVIIIth Colloque James Joyce, “'It gested': Geste and Gesticulation”, I.T.E.M (Institute of Texts and Manuscripts) and Université de Paris III-Sorbonne-Nouvelle, Ecole Normale Supérieure, Paris, 24 May.

Bolens, Guillemette. 2012. The Style of Gestures: Embodiment and Cognition in Literary Narrative. Baltimore: Johns Hopkins University Press.

Burns, Christy L. 2000. Gestural Politics: Stereotype and Parody in Joyce. New York: State University of New York Press. Colum, Mary, and Patrick. 1959. Our Friend James Joyce. London: Victor Gollancz.

Cope, Jackson L. 1962. The Rhythmic Gesture: Image and Aesthetic in Joyce's Ulysses. EHL 29: 67-89. [CrossRef] Freud, Sigmund. 2003. Psychopathology of Everyday Life. Translated by A.A. Brill. New York: Dover Publications. Goldberg, Samuel Louis. 1961. The Classical Temper: A Study of James Joyce's Ulysses. London: Chatto \& Windus.

Hayman, David. 1993. Language of/as Gesture in Joyce. In James Joyce: A Collection of Critical Essays. Edited by Mary T. Reynolds. Upper Saddle River: Prentice Hall.

Hendry, Irene. 1946. Joyce's Epiphanies. The Sewanee Review 54: 449-67.

Joyce, James. 1956. Epiphanies. Buffalo: Lockwood Memorial Library.

Joyce, James. 1963. Stephen Hero. Edited by Manuscript in the Harvard College Library by Theodore Spencer. New York: New Directions Publishing.

Joyce, James. 1991. Poems and Shorter Writings. Edited by Richard Ellmann, A. Walton Litz and John Whittier-Ferguson. London: Faber and Faber.

Joyce, James. 2008. Occasional, Critical, and Political Writing. Edited by Kevin Barry. Oxford: Oxford University Press. Joyce, Stanislaus. 2009. My Brother's Keeper: James Joyce's Early Years. Boston: Da Capo Press.

Kristeva, Julia. 1978. Gesture: Practice or Communication. In The Body Reader. Social Aspects of the Human Body. Edited by Ted Polheums. New York: Pantheon Books.

Martin, William. 2012. Joyce and the Science of Rhythm. New York: Palsgrave MacMillan.

Merleau-Ponty, Maurice. 1945. Phénoménologie de la Perception. Paris: Gallimard.

Merleau-Ponty, Maurice. 1960. Signes. Paris: Gallimard.

Milesi, Laurent. 2009. James Joyce and the Difference of Language. Cambridge: Cambridge University Press.

Milesi, Laurent. 2010. Joycean Choreo-Graphies in Stephen Hero and A Portrait of the Artist as a Young Man. In Hypermedia Joyce. Edited by David Vichnar and Louis Armand. Prague: Litteraria Pragensia, pp. 103-9.

Naas, Michael. 1996. Blanchot ... Writing ... Ellipses. Qui Parle 10: 89-112.

Natali, Ilaria. 2011. A Portrait of James Joyce's Epiphanies as a Source Text. Available online: humannicus.org (accessed on 1 November 2018).

Nichols, Ashton. 1978. The Poetics of Epiphany: Nineteenth Century Origin of the Literary Movement. Tuscaloosa: University of Alabama Press.

Nolan, Carrie. 2009. Agency and Embodiment. Cambridge: Harvard University Press.

Noon, William T. 1957. Joyce and Aquinas. New Haven: Yale University Press.

OED. 2018. Oxford English Dictionary Online. Oxford University Press. Available online: www.oed.com (accessed on 1 November 2018).

Paraskeva, Anthony. 2013. The Speech-Gesture Complex: Modernism, Theatre, Cinema. Edinburgh: Edinburgh University Press.

Rasula, Jed. 1997. Finnegans Wake and the Character of the Letter. James Joyce Quarterly 34: 517-30.

Scholes, Robert. 1964. Joyce and the Epiphany: The Key to the Labyrinth? The Sewanee Review 72: 65-77.

Schotter, Jesse. 2010. Verbivocovisual: James Joyce and the Problem of Babel. James Joyce Quarterly 48: 89-109. [CrossRef]

Slote, Sam. 2005. Epiphanic "Proteus". Genetic Joyce Studies 5. Available online: jeneticjoycestudies.org (accessed on 1 November 2018).

Volpone, Annalisa. 2014. The Poetics of the Unsaid: Joyce's Use of Ellipses between Meaning and Suspension. European Joyce Studies 23: 87-108.

Weir, David. 1996. James Joyce and the Art of Mediation. Ann Arbor: University of Michigan Press.

Weir, Lorraine. 1977. The Choreography of Gesture: Marcel Jousse and Finnegans Wake. James Joyce Quarterly 14: 313-25. 
Whaley, Helen R. 1970-1977. The Role of the Blind Piano Tuner in Joyce's Ulysees. Modern Fiction Studies 16: 531-35.

Zahavi, Dan. 2007. Expression and Empathy. In Folk Psychology Reassessed. Edited by Daniel D. Hutto and Matthew Ratcliffe. Dordrecht: Spinger, pp. 25-40. 